4 Abstract

\title{
Study of seismic diffractions caused by a fracture zone at In Salah Carbon dioxide storage project
}

\author{
Rui Zhang ${ }^{1}$, Donald Vasco ${ }^{2}$, Thomas M Daley ${ }^{2}$
}

The In Salah $\mathrm{CO}_{2}$ storage project in Algeria has injected over 3 million tonnes of carbon dioxide into a water filled tight sand formation. Interferometric Synthetic Aperture Radar (InSAR) range change data revealed a double lobbed pattern of deformation that has been modeled as the opening of a sub-vertical fracture, or damage, zone. The location and geometry of the linear feature were subsequently verified using a seismic reflection survey. The elastic properties of the fracture zone, including anisotropic Poisson ratio $(\nu)$, Young's $(\mathrm{E})$ and shear $(\mathrm{G})$ moduli, were estimated from coupled geomechanical and hydrological modeling of surface deformation and pressure variations in the injection well. The elastic moduli reflect the fracture properties after $\mathrm{CO}_{2}$ flow through the fracture zone. Thus, the seismic signature of the fracture zone could be used for monitoring the $\mathrm{CO}_{2}$ plume. Using the estimated fracture model, we built two and three dimensional models consisting of an anisotropic fracture zone embedded within an isotropic background. Finite-difference modeling of seismic shot gathers allows us to estimate the effects of scattering from the fracture zone, potentially further constraining the geomechanical model. From the seismic modeling results, we find diffracted waves, induced by the fracture zone, which behave similar

\footnotetext{
${ }^{1}$ Presently University of Louisiana at Lafayette, Lafayette, Louisiana; for-

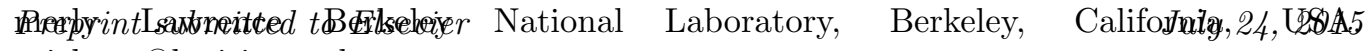
ruizhang@louisiana.edu

${ }^{2}$ Lawrence Berkeley National Laboratory, California, USA
} 
1 to point source diffractions. This modeling is intended to guide a search for 2 diffraction events in the 3D surface seismic field data. The modeling results 3 indicate that using the moduli estimated from geomechanical modeling, frac4 ture scattered events would be 100 times lower amplitude than the interface 5 reflections, and thus would be hard to detect. While diffracted waves are ob6 served in the field data, which may imply the need for revision of the fracture 7 model, including shape and elastic moduli, we are not able to match the field 8 observation whith our modeled events. This work presents a frontier study 9 on the integration of geomechanical and geophysical methods at the In Salah 10 site as a means to test the estimate of the subsurface $\mathrm{CO}_{2}$ flooded fracture properties.

Keywords: geological $\mathrm{CO}_{2}$ sequestration; In Salah project; finite difference; seismic wave propagation; fracture

\section{Introduction and background}

Understanding and diagnosing the presence of high permeability fracture or damage zones is an important component of carbon storage, especially for industrial scale projects. The In Salah Gas project (a joint venture between Sonatrach, BP, and StatoilHydro) located in the central region of Algeria is one of the world's first industrial scale $\mathrm{CO}_{2}$ storage projects and first to be associated with a producing gas field (Fig. 1). Natural gas produced from the Krechba field is high in $\mathrm{CO}_{2}$ which is separated and injected into the water leg of the field for geological storage. Over a period of about 8 years, 0.5 to 1.0 million tons of $\mathrm{CO}_{2}$ per year had been injected into a $20 \mathrm{~m}$ thick, water-filled, carboniferous formation with a relatively low permeability. 
1 Three wells with 1 to $1.5 \mathrm{~km}$ long horizontal sections, located at a depth of 2 approximately $2 \mathrm{~km}$, serve as the injectors (Mathieson et al., 2009).

During the first five years of injection (2004-2007) ground deformation was 4 monitored using Interferometric Synthetic Aperture Radar (InSAR) range 5 changes obtained from the orbiting European Space Agencies C-band satel6 lites (Vasco et al., 2008). The range is the distance between points on the 7 surface of the Earth and a reference point, associated with the baseline posi8 tion of the satellite. The observations reveal changes of $5-10 \mathrm{~mm}$ per year over each of the injection wells (KB-501, KB-502, and KB-503 in Fig. 2a). Fig. 2a shows 5 years of accumulated range change, where red color represents uplift of the surface, which has been utilized to infer flow within both the reservoir and a sub-vertical fault/fracture zone intersecting well KB-502 (Vasco et al., 2010). In addition to InSAR measurements, 3D surface seismic data were acquired over the same area in two surveys, the first in 1997 and the second in 2009 (Gibson-Poole and Raikes, 2010). Fig. 2a shows the footprint of surface seismic data coverage from 2009. The 3D seismic interpretation at In Salah has mapped multiple horizons related to specific geological formations, with six of them labeled in Fig. 2b. Among those is the C10.2 the reservoir interval into which the carbon dioxide was injected, and two shallower horizons (C20.1 and C20.4) are the base and top of a 900m thick cap rock. A recent study by using the InSAR and 3D seismic data sets shows good spatial correlation between the ground surface uplift and subsurface seismic attributes mapping, indicating the existence of a fracture zone which possibly allows the upward flow of $\mathrm{CO}_{2}$ (Zhang et al., 2015). Understanding the properties of subsurface fracture zones, and the impact of $\mathrm{CO}_{2}$ entering 
those zones, is important for the In Salah project and, in general, for Carbon Capture and Storage (CCS).

In this paper, we shall study the seismic diffraction response of a suspected fracture zone using properties based on geomechanical modeling of well pressure data and InSAR range changes, thus testing the ability of seismic data to constrain the geomechanical model of a fracture zone derived from nonseismic data. Because the fracture properties are estimated for a model of $\mathrm{CO}_{2}$ flooding the fracture zone, the seismic response indicates our ability to monitor the $\mathrm{CO}_{2}$ plume with time-lapse change in seismic diffraction. Such diffraction wave response from a narrow fracture zone can be utilized to image and characterize the fracture zone by diffraction imaging technique. Diffraction imaging had been developed to detect small size subsurface objects (Landa et al., 1987; Kanasewich and Phadke, 1988; Tsingas et al., 2011) based on coherent summation of diffracted events using an appropriate traveltime description in common-offset and common-midpoint domains. Landa and Keydar (1998) use common-diffraction-point sections for imaging of diffraction energy and detection of local heterogeneities. Berkovitch et al. (2009) present a technique that is based on the multifocusing method. A similar idea is proposed by Dell and Gajewski (2011), who use the commonreflection surface operator. Several papers propose diffraction enhancement by modifying pre-stack Kirchhoff depth migration using appropriate weighting (Kozlov et al., 2004; Moser and Howard, 2008; Koren and Ravve, 2011). A narrow zone in which the seismic reflections are pushed down, or delayed in time, is observed by comparing two time-lapse seismic datasets in 1997 and 2009 above the injection well KB-502 (Figure 3). The first sur- 
vey in 1997 was used for hydrocarbon exploration and the recent survey in 2009 was conducted for $\mathrm{CO}_{2}$ sequestration research. Although two seismic surveys were not designed for time-lapse analysis and there is a systematic discrepancy between them, we are able to see such a push-down after the alignment (Zhang et al., 2013, 2014). The time delay of the push-down event is approximately $13 \mathrm{~ms}$, interpreted as the result of velocity changes induced by injection of carbon dioxide, are shown in Fig. 3 for cross-line 1323. Zhang et al. (2015) recently presented an integration study of seismic attributes and InSAR datasets, which demonstrated the existence of the fracture zone. The fracture zone was confirmed from the spatial correlation between the pushdown from the seismic reflection (indicated by two black dashed arrows in Figs. 4a and b), a double-line feature from the positive curvature attribute result (Figs. 4c and d), and surface uplift (Fig. 2a). The black solid line represents horizontal portion of the injection well KB-502. The double-line feature from the most positive curvature has been interpreted as the parallel boundaries of the fracture zone. Thus, the width between the double lines and their lengths leads to our estimations of the size of the fracture zone.

The above post-stack seismic image was derived from a multi-step workflow, including several techniques to suppress noise because the raw data are noise contaminated. The possible diffraction wave generated from the fracture zone would also be suppressed as noise. Thus, to study the diffraction wave, we have to look at the pre-stack data. Fig 5 shows an unmigrated common middle point gather located at the south side of the fracture zone. Because the diffraction wave generated by the fracture zone acts similarly as point source diffraction wave, it arrive earlier at far offset which is close to 
the fracture zone and later at near offset, which is away from the fracture zone.The blue dashed line highlights the reflection wave from interpreted horizon C10.2. The event indicated by the pink dashed line has been interpreted as the diffraction wave. As expected, the fracture acted as a point reflector at a depth a little shallower than the C10.2, and the diffraction wave arrived earlier at far offset than near offset. The purpose of this study is to reproduce the diffraction wave by seismic modeling method. In this way, we can evaluate the possibility of monitoring the $\mathrm{CO}_{2}$ flow through the fracture zone.

Before presenting our modeling results, we first review evidence for the damage zone in the inversion of the InSAR data by Vasco et al. $(2008,2010)$ and the geomechanical modeling of Rutqvist (2012) and Rinaldi and Rutqvist (2013). Next, we describe the exact elastic properties used for modeling, and then present two- and three-dimensional finite difference seismic modeling results.

\section{InSAR Interpretation and Geomechanical modeling}

jection at well KB-501, located to the south of this study area, was used to image a linear, high permeability zone within the reservoir that appeared to correlate with an interpreted fault (Vasco et al., 2008). Vasco et al. (2010), 
2 a hydrofracture (Davis, 1983), interpreted the range change data associated

3 with the injection at KB-502 in terms of variable aperture change on a verti4 cal fault/fracture (damage) zone. In that study it was found that the InSAR 5 range change observations could be fit by a model in which the largest aper6 ture changes were concentrated around the injector. Because the reservoir 7 is situated in a low velocity zone within the model, it proved important to 8 accurately model the variations in elastic properties as a function of depth 9 (Vasco et al., 2010). In order to match two components of InSAR displace-

ment, quasi-eastwest and quasi-vertical, Rucci et al. (2013) required variable aperture and volume change on sub-vertical damage zones intersecting all three of the injectors. As in the earlier studies, the data could be satisfied by changes concentrated around the injection interval.

Rutqvist et al. (2010), Rutqvist (2012) and Rinaldi and Rutqvist (2013) incorporated coupled hydrological and geomechanical modeling to estimate 3D elastic properties of the fracture plane. Based upon the InSAR analysis, the fracture zone was modeled as a narrow vertical zone. Fig. 6a shows the entire geomechanical model and Fig. 6b shows a detailed view of the fracture. The zone around the injection well (KB-502) is plotted as a white region while the fracture zone is plotted as a purple rectangle. The geomechanical modeling was used to estimate Young's moduli along the three axes $\left(E_{x}, E_{y}\right.$ and $\left.E_{z}\right)$, and similarly the shear moduli $\left(G_{x y}, G_{x z}\right.$ and $\left.G_{y z}\right)$ and Poisson's ratios $\left(\nu_{x y}, \nu_{x z}\right.$ and $\left.\nu_{y z}\right)$ of the fracture zone (Table 1 is from Table 3 in Rinaldi and Rutqvist, 2013). The success of the modeling of Rinaldi and Rutqvist (2013) encouraged us to utilize the geomechanical parameters for seismic 
waveform modeling. By using the same material properties for geomechanical 2 and seismic modeling, we can test the validity of the fracture properties with independent measures (surface seismic and InSAR).

\begin{tabular}{lr} 
Table 1: Properties of fracture zone \\
\hline \hline Property & Value \\
\hline Length & $3500 \mathrm{~m}$ \\
Height & $350 \mathrm{~m}$ \\
Total width & $80 \mathrm{~m}$ \\
$E_{x}$ & $0.17 \mathrm{GPa}$ \\
$E_{y}$ & $0.14 \mathrm{GPa}$ \\
$E_{z}$ & $1.0 \mathrm{GPa}$ \\
$G_{x y}, G_{x z}, G_{y z}$ & $1.0 \mathrm{GPa}$ \\
$\nu_{x y}, \nu_{x z}$ & 0.18 \\
$\nu_{y z}$ & 0.25 \\
\hline
\end{tabular}

3

\section{3. Isotropic and orthotropic elasticity}

5 Seismic wave propagation modelling is governed by constitutive relations 6 of linear elasticity. The particular stress-strain relationship is given by a 7 generalized Hooke's law which linearly relates the stress and strain through 8 the stiffness and/or compliance tensors (Nemat-Nasser and Hori, 1999). Eq.

91 shows classical stress $(\sigma)$ and strain $(\epsilon)$ relationships in term of stiffness 10 tensor matrix $(\mathbf{C})$ and compliance matrix $(\mathbf{S})$, which also shows inverse re11 lationship between $\mathbf{C}$ and $\mathbf{S}$.

$$
\begin{aligned}
& \sigma=\mathbf{C} \cdot \epsilon \\
& \epsilon=\mathbf{S} \cdot \sigma \\
& \mathbf{C}=\mathbf{S}^{-1}
\end{aligned}
$$


1 As in the geomechanical modeling of Rinaldi and Rutqvist (2013), we as2 sume a layered isotropic background model. Thus, its stiffness tensor matrix $3 \mathrm{C}$ can be expressed in terms of $\mathrm{P}$-wave velocity $\left(V_{p}\right)$, S-wave velocity $\left(V_{s}\right)$ 4 and density $(\rho)$ (Eq. 2). These parameters can be estimated from well-log 5 measurements.

$$
[C]=\left[\begin{array}{cccccc}
V_{p}^{2} \rho & \left(V_{p}^{2}-2 V_{s}^{2}\right) \rho & \left(V_{p}^{2}-2 V_{s}^{2}\right) \rho & 0 & 0 & 0 \\
\left(V_{p}^{2}-2 V_{s}^{2}\right) \rho & V_{p}^{2} \rho & \left(V_{p}^{2}-2 V_{s}^{2}\right) \rho & 0 & 0 & 0 \\
\left(V_{p}^{2}-2 V_{s}^{2}\right) \rho & \left(V_{p}^{2}-2 V_{s}^{2}\right) \rho & V_{p}^{2} \rho & 0 & 0 & 0 \\
0 & 0 & 0 & V_{s}^{2} \rho & 0 & 0 \\
0 & 0 & 0 & 0 & V_{s}^{2} \rho & 0 \\
0 & 0 & 0 & 0 & 0 & V_{s}^{2} \rho
\end{array}\right]
$$

6 Following the geomechanical modeling results, the fracture zone is repre7 sented as an orthotropic elastic zone. Such orthotropic elastic media display 8 symmetric anisotropic properties with 9 independent parameters. The frac9 ture zone compliance matrix (S) can be expressed in term of elastic moduli, 10 Young's modulus (E), shear modulus $(\mathrm{G})$ and Poisson's ratio $(\nu)$, as shown 11 in Eq. 3.

$$
[S]=\left[\begin{array}{cccccc}
1 / E_{x} & -\nu_{y x} / E_{y} & -\nu_{z x} / E_{z} & 0 & 0 & 0 \\
-\nu_{x y} / E_{x} & 1 / E_{y} & -\nu_{z y} / E_{z} & 0 & 0 & 0 \\
-\nu_{x z} / E_{x} & -\nu_{y z} / E_{y} & 1 / E_{z} & 0 & 0 & 0 \\
0 & 0 & 0 & 1 / G_{y z} & 0 & 0 \\
0 & 0 & 0 & 0 & 1 / G_{x z} & 0 \\
0 & 0 & 0 & 0 & 0 & 1 / G_{x y}
\end{array}\right]
$$


1 Because of the symmetric elasticity, the compliance matrix has to be symmet2 ric following Eq. 4. The stiffness matrix is then the inverse of the compliance 3 matrix.

$$
\begin{aligned}
& S_{12}=S_{21}=\frac{\nu_{y x}}{E_{y}}=\frac{\nu_{x y}}{E_{x}} \\
& S_{13}=S_{31}=\frac{\nu_{z x}}{E_{z}}=\frac{\nu_{x z}}{E_{x}} \\
& S_{23}=S_{32}=\frac{\nu_{z y}}{E_{z}}=\frac{\nu_{y z}}{E_{y}}
\end{aligned}
$$

${ }_{4}$ Thus, the 3D stress strain relationship for seismic wave propagation can be 5 written as (Virieux, 1986b, Etgen, 1987, Daley et al., 2006):

$$
\left[\begin{array}{c}
\sigma_{x x} \\
\sigma_{y y} \\
\sigma_{z z} \\
\sigma_{y z} \\
\sigma_{x z} \\
\sigma_{x y}
\end{array}\right]=\left[\begin{array}{cccccc}
C_{11} & C_{12} & C_{13} & 0 & 0 & 0 \\
C_{21} & C_{22} & C_{23} & 0 & 0 & 0 \\
C_{31} & C_{32} & C_{33} & 0 & 0 & 0 \\
0 & 0 & 0 & C_{44} & 0 & 0 \\
0 & 0 & 0 & 0 & C_{55} & 0 \\
0 & 0 & 0 & 0 & 0 & C_{66}
\end{array}\right] \times\left[\begin{array}{c}
\epsilon_{x x} \\
\epsilon_{y y} \\
\epsilon_{z z} \\
2 \epsilon_{y z} \\
2 \epsilon_{x z} \\
2 \epsilon_{x y}
\end{array}\right]
$$

$6 \quad$ Our numerical implementation of seismic wave propagation is realized 7 on a discrete grid using an explicit finite-difference technique, which was 8 introduced by Madariaga (1976), Virieux and Madariaga (1982), Virieux 9 (1986a). The inclusion of fractures follows the method of Coates and Schoen- 
1

2

$3 \mathrm{X}-\mathrm{Z}$ plane across the fracture zone. The $2 \mathrm{D}$ model is 5000 meters in width,

42000 meters in depth with $5 \times 5 \mathrm{~m}^{2}$ size cell (Fig. 7). Two horizons have

5 been used in the construction of the $2 \mathrm{D}$ background isotropic model, which

6 represent two major seismic reflections (black arrows). The 2D elastic prop-

7 erties are constructed by interpolating and extrapolating available well-log

8 data (well KB-5) along these horizons (Fig. 2b). The well-log data, including

9 Gamma ray, Resistivity, $V_{p}, V_{s}$, density $(\rho)$ and Poisson's ratio $(\nu)$, are shown

10 in Fig. 8. The Vp, Vs and density logs are used to calculated isotropic stiff-

11 ness tensor components $C_{11}, C_{12}, C_{22}$ and $C_{33}$, following Eq. 2. Because the

12 fracture zone is nearly perpendicular to the model plane, it is placed in the

13 middle of the plane right above the $\mathrm{C} 10.2$ horizon(black dashed rectangles in

${ }_{14}$ Fig. 7). As discussed previously, the orthotropic compliance tensor for the

15 fracture zone is calculated from moduli $\left(E_{x}, E_{z}, G_{x z}\right.$ and $\nu_{x z}$ in Table 1),

16 leading to the compliance matrix $(\mathrm{S})$ in Eq. 6.

$$
[S]=\left[\begin{array}{ccc}
1 / E_{x} & -\nu_{z x} / E_{z} & 0 \\
-\nu_{x z} / E_{x} & 1 / E_{z} & 0 \\
0 & 0 & 1 / G_{x z}
\end{array}\right]=\left[\begin{array}{ccc}
5.88 & -1.06 & 0 \\
-1.06 & 1.0 & 0 \\
0 & 0 & 1.0
\end{array}\right]
$$


1 Thus, the compliance matrix is inverted into the 2D stiffness tensor matrix 2 (C), as shown in Eq. 7.

$$
[C]=\left[\begin{array}{ccc}
0.21 & 0.22 & 0 \\
0.22 & 1.24 & 0 \\
0 & 0 & 1.0
\end{array}\right] G P a
$$

$3 \quad$ For the modeling, a wavelet with center frequency of $30 \mathrm{~Hz}$ is used as 4 a vertical source placed $1 \mathrm{~km}$ from the left boundary. Fig. 9 shows four 5 snapshots of wavefields of the vertical component. The incidence wave first 6 reaches the fracture zone at about $0.8 \mathrm{~s}$ and a diffracted wave is generated. 7 From the wavefield of the diffracted wave, we find the fracture zone behaves 8 like a point source rather than conventional reflection. The conventional 9 reflection wavefields from horizons $\mathrm{C} 30$ and $\mathrm{C} 10.2$ are indicated by red dashed

arrows (Figs. 9a and b). The diffracted wavefields caused by the fracture are highlighted with black dashed ellipse in Figs. 9b, and are indicated by black dashed arrows in Figs. 9c and d.

Seismograms has been generated for both horizontal and vertical components on the surface (Fig. 10). Figs. 10a, b and c show vertical component received seismograms for models with fracture embedded, without fracture and their difference. Figs. 10d, e and f show horizontal component received seismograms for models with fracture embedded, without fracture embedded and their difference. The figures are plotted with proportional amplitude for clear display. We observed the seismograms' horizontal components (Figs. 10d and e) are about twice the amplitude of vertical component (Figs. 10a and b), and 10 times the amplitude of differences (Figs. 10c and f). Differ- 

8 in Figs. 10.

ences are caused by the fracture zone, and appear low amplitude compared with conventional reflection (yellow dashed arrows in Figs 10a and d). We also observe that the horizontal component diffraction is stronger than the vertical component. The black arrows point out boundary reflections, which have not been fully suppressed by PML. By comparing with post-stack seismic imaging and interpretation, we have identified two hyperbolic events as reflection from C30 and C10.2, which are pointed out by red dashed arrows

\section{3D Modeling}

Following 2D modeling, we implemented 3D seismic modeling to look at azimuthal fracture response and to better compare with field data. The 3D model is 3000 meters in $\mathrm{X}$ and $\mathrm{Y}$ direction (within the blue dashed rectangle in Fig. 6b), 2000 meters in depth, and has $5 \times 5 \times 5 \mathrm{~m}^{3}$ cell size. Fig. 11 shows the 3D isotropic model of $V_{p}$, which was constructed by interpolating well-log measurements (from well KB-5) along interpreted horizons. This $V_{p}$ model is used to construct the model's isotropic stiffness tensors following Eq. 2. The fracture zone has been placed at the location obtained from geomechanical modeling. The compliance matrix of the fracture plane is also derived from geomechanical modeling results (elastic moduli in Table 1), following Eq. 3, and is shown in Eq. 8. 


$$
[S]=\left[\begin{array}{cccccc}
5.88 & -1.06 & -1.06 & 0 & 0 & 0 \\
-1.06 & 7.14 & -1.79 & 0 & 0 & 0 \\
-1.06 & -1.79 & 1.0 & 0 & 0 & 0 \\
0 & 0 & 0 & 1.0 & 0 & 0 \\
0 & 0 & 0 & 0 & 1.0 & 0 \\
0 & 0 & 0 & 0 & 0 & 1.0
\end{array}\right]
$$

1 The stiffness tensors matrix is then derived by inverting the Eq. 8 into Eq. 29.

$$
[C]=\left[\begin{array}{cccccc}
0.39 & 0.30 & 0.95 & 0 & 0 & 0 \\
0.30 & 0.48 & 1.17 & 0 & 0 & 0 \\
0.95 & 1.17 & 4.10 & 0 & 0 & 0 \\
0 & 0 & 0 & 1.0 & 0 & 0 \\
0 & 0 & 0 & 0 & 1.0 & 0 \\
0 & 0 & 0 & 0 & 0 & 1.0
\end{array}\right] G P a
$$

$3 \quad$ In preparation for future comparison with field data, the seismic modeling 4 results are generated according to the real field data acquisition geometry. 5 One shot gather geometry, crossing the fracture zone, is selected to test 6 our modeling. The acquisition geometry in map view is shown in Fig. 12. 7 The seismic source is located at the red point and receivers are at blue dots 8 which are sorted in 11 lines, as labeled in Fig. 12a. Double black lines in Fig. 9 12a highlight the boundary of the fracture zone. Fig. 12b shows wavefield 10 of vertical component at time $0.5 \mathrm{~s}$ in a map view, where green points are 11 receivers's locations.

12 The vertical component of the modeled seismograms are shown in Fig. 
1 13. Fig. 13a shows the shot gather with embedded fracture; Fig. 13b shows 2 the shot gather without the fracture and Fig. 13c shows their difference. In 3 Fig. 13a, the head wave is indicated by the white arrow; two major reflections 4 are indicated by black arrows and the surface waves are indicated by yellow 5 arrows. As expected, these seismic events arrive first at line 11 and last at 6 line 1. The difference is calculated by subtracting Fig. 13a from Fig. 13b, 7 and is assumed to be caused by the fracture zone. To clearly display the 8 difference in Fig. 13c, its colorbar is scaled differently from Figs. 13a and 9 b. Fig 13 shows that the fracture induced diffracted wave is about 1/100 of 10 the conventional seismic events amplitude. We noticed that the first breaks

of the diffraction wave in Fig. 13c arrive slightly earlier at line 1 and later at line 11. We also found strong amplitude variation at the first arrival of the diffraction wave (eg. red arrows in Fig. 13c). A different pattern of diffraction waves are indicated by orange arrows in Fig. 13c, which could be caused by the end of the fracture plane.

The vertical component shot gathers of line 11 in Fig. 13 are selected to compare the reflection and diffraction amplitudes. Two major reflections and the first arrival of the diffracted waves are indicated by yellow lines, labeled as 1,2 and 3 in Fig. 14. The average peak amplitudes of these three events have been calculated, as $A v g a m p_{1}=0.4949$, Avgamp $_{2}=0.3758$, Avgamp $_{3}=$ 0.0033 respectively. Trace No. 10 in Figs. 14a and b are overlain plotted in lower plot in Fig. 15, where the red seismogram is the modeled data with the embedded fracture and the black seismogram is without fracture. The upper two plots show enlarged views of the seismograms around the first and last arrival of the diffractions. 
As stated previously, the shot gathers follow the real seismic acquisition geometry in Fig. 12. We present a comparison between raw field data and our modeling results in Fig. 16. It shows that the head waves (black arrows), first reflection waves (yellow arrows) and surface waves (red arrows) fit well between real and modeled datasets. Because the noise level is very high in field shot gathers and the expected diffraction wave is weak, it is still difficult to identify diffraction in the field data. However, we still can see some visible relative flat events in the line 11 of Fig. 16a (indicated by the yellow dashed ellipse), which is comparable to the diffraction wave events in Fig. 13c. This is leading to our future work to identify these events as diffractions, separate from reflections for characterizing the fracture zone.

\section{Discussions}

The coupled geomechanical modeling of Rinaldi and Rutqvist (2013) includes multiphase flow for supercritical $\mathrm{CO}_{2}$ and brine, by using simulator TOUGH-FLAC (Rutqvist and Tsang, 2002). These coupled models require a large number of input parameters that might not be readily available, such as parameters for geomechanical-hydrological interactions. In fact, the simplified four-layer model were used for studying subsets of coupled processes. However, such model could only generate three reflections, which is inappropriate to study the seismic response, especially compared to field data. Thus, a detailed background model generated from sonic log is used in this paper to determine the influence of a fracture zone on wave propagation.

Based on our modeling results, the diffraction amplitudes are very weak compared to the reflection amplitudes, as expected. In our study on In Salah 
1 fracture zone, the modeled amplitude of the diffraction wave, using static 2 moduli for the fracture zone derived from geomechanical modeling, is about 30.01 times of the primary reflection wave amplitudes. However, this result 4 is based on the current characterization of the fracture zone which includes 5 the estimated size, shape and static elastic properties.

$6 \quad$ In this paper, the 2D and 3D modeling results shown in Figs. 10 and 713 are presented as common shot gahters, which are different from the field 8 data common middle point gather in Fig. 5. As known, the common middle 9 point gather can be sorted from many shot gathers, each of which needs a 10 full 3D simulation. Further analysis of the 3D field data could investigate the amplitude of diffractions for comparison to the geomechanical moduli model.

\section{Summary and Conclusions}

We have modeled seismic wave propagation to investigate the effects of a fracture zone at the In Salah $\mathrm{CO}_{2}$ storage site. The fracture properties are based on geomechanical modeling which estimated the fracture geometry and elastic properties. Our seismic modeling shows the geomechanical model of a vertical fracture zone at In Salah can generate diffraction waves, which are similar to a point source signature in the subsurface. The relative amplitude of diffraction waves and reflection waves is shown to $1 / 100$, indicating that discrete scattered events from a fracture zone with the geomechanical model properties would be quite weak and difficult to observe or image. It is important to note that since the shape and static elastic properties of the fracture zone comes from geomechanical modeling these parameters could be revised by future interpretation of scattering in the seismic field data. 
1 For example, a joint inversion of seismic and surface uplift datasets could be 2 used to improve the characterization of the fracture zone. Our results may 3 be considered as a static moduli limit for the expected elastic effects of the 4 fracture zone for an initial model of the fracture shape. This work represents 5 an effort to integrate seismic and geomechanical methodologies at this site, 6 allowing further constraints on fracture properties, and also providing input 7 to design of future monitoring surveys.

\section{8. Acknowledgement}

This work was supported by the InSalah Joint Industry Project (JIP), a partnership of BP, Statoil and Sonatrach, from 2011-2013. This work was partially supported by the GEOSEQ project for the Assistant Secretary for Fossil Energy, Office of Coal and Power Systems through the National Energy Technology Laboratory, of the U.S. Department of Energy, under contract No. DE-AC02-05CH11231. Some of the seismic data processing in this report was performed using the VISTA software package provided by GEDCO, now a Schlumberger company, potentially allowing further constraints on fracture properties, and also providing input to design of future monitoring surveys. The authors would like to thank the many colleagues who worked on the In Salah $\mathrm{CO}_{2}$ storage project, including: Iain Wright, Allan Mathieson, Philip Ringrose, Britta Paasch, Rob Bissell, Kevin Dodds, Stephen Cawley, Olav Hansen, Lykke Gemmer, Volker Oye, Alessandro Ferretti, Kamran Iranpour, Nabil Saoula, John Midgley, Quanlin Zhou, Victor Leung, Ramsey Haught and Karl Kappler, with apologies to any not mentioned. 
1

2

4

5

6

7

\section{References}

Berkovitch, A., Belfer, I., Hassin, Y., Landa, E., 2009. Diffraction imaging by multifocusing. GEOPHYSICS 74 (6), WCA75-WCA81.

URL http://library.seg.org/doi/abs/10.1190/1.3198210

Coates, R., Schoenberg, M., 1995. Finite?difference modeling of faults and fractures. GEOPHYSICS 60 (5), 1514-1526.

URL http://dx.doi.org/10.1190/1.1443884

Daley, T., Schoenberg, M., Rutqvist, J., Nihei, K., 2006. Fractured reservoirs: An analysis of coupled elastodynamic and permeability changes from porepressure variation. Geophysics 71 (5), O33-O41.

URL http://library.seg.org/doi/abs/10.1190/1.2231108

Davis, P. M., 1983. Surface deformation associated with a dipping hydrofracture. Journal of Geophysical Research: Solid Earth 88 (B7), 5826-5834.

URL http://dx.doi.org/10.1029/JB088iB07p05826

Dell, S., Gajewski, D., 2011. Common-reflection-surface-based workflow for diffraction imaging. Geophysics 76 (5), S187-S195.

URL http://geophysics.geoscienceworld.org/content/76/5/S187 . abstract

Etgen, J., 1987. Finite difference elastic anisotropic wave propagation.

Gibson-Poole, C. M., Raikes, S., 2010. Enhanced understanding of $\mathrm{CO}_{2}$ storage at krechba from 3d seismic. In: 9th Annual Conference on Carbon Capture and Sequestration. Pittsburgh, PA. 
1 Kanasewich, E. R., Phadke, S. M., 1988. Imaging discontinuities on seismic

$2 \quad$ sections. Geophysics 53 (3), 334-345.

3 URL http://geophysics.geoscienceworld.org/content/53/3/334. abstract

4 Komatitsch, D., Martin, R., 2007. An unsplit convolutional Perfectly 5 Matched Layer improved at grazing incidence for the seismic wave equa$6 \quad$ tion. Geophysics 72 (5), SM155-SM167.

7 Koren, Z., Ravve, I., 2011. Full-azimuth subsurface angle domain wavefield 8 decomposition and imaging part i: Directional and reflection image $9 \quad$ gathers. Geophysics 76 (1), S1-S13. URL http://geophysics.geoscienceworld.org/content/76/1/S1 . abstract 
the Seismological Society of America 66 (3), 639-666.

URL http://www . bssaonline.org/content/66/3/639. abstract

Martin, R., Komatitsch, D., 2009. An unsplit convolutional perfectly matched layer technique improved at grazing incidence for the viscoelastic wave equation. Geophysical Journal International 179 (1), 333-344.

Martin, R., Komatitsch, D., Ezziani, A., 2008a. An unsplit convolutional perfectly matched layer improved at grazing incidence for seismic wave equation in poroelastic media. Geophysics 73 (4), T51-T61.

Martin, R., Komatitsch, D., Gedney, S. D., 2008b. A variational formulation of a stabilized unsplit convolutional perfectly matched layer for the isotropic or anisotropic seismic wave equation. Computer Modeling in Engineering and Sciences 37 (3), 274-304.

Mathieson, A., Wright, I., Roberts, D., Ringrose, P., 2009. Satellite imaging to monitor $\mathrm{CO}_{2}$ movement at krechba, algeria. Energy Procedia 1 (1), 2201 - 2209, greenhouse Gas Control Technologies 9 Proceedings of the 9th International Conference on Greenhouse Gas Control Technologies (GHGT-9), November 2008, Washington DC, USA.

URL http://www.sciencedirect.com/science/article/pii/S1876610209002872

Moser, T., Howard, C., 2008. Diffraction imaging in depth. Geophysical Prospecting 56 (5), 627-641.

URL http://dx.doi.org/10.1111/j.1365-2478.2007.00718.x

Nemat-Nasser, S., Hori, M., 1999. Micromechanics: overall properties of heterogeneous materials. Vol. 2. Elsevier Amsterdam. 
1 Rinaldi, A. P., Rutqvist, J., 2013. Modeling of deep fracture zone opening and transient ground surface uplift at KB-502 $\mathrm{CO}_{2}$ injection well, In Salah, Algeria. International Journal of Greenhouse Gas Control 12 (0), $155-167$.

URL http://www.sciencedirect.com/science/article/pii/S1750583612002502

Roden, J. A., Gedney, S. D., 2000. Convolution PML (CPML): An efficient FDTD implementation of the CFS-PML for arbitrary media. Microwave and Optical Technology Letters 27 (5), 334-339.

Rucci, A., Vasco, D. W., Novali, F., 2013. Monitoring the geologic storage of carbon dioxide using multicomponent sar interferometry. Geophysical Journal International 193 (1), 197-208.

URL http://gji.oxfordjournals.org/content/193/1/197.abstract

Rutqvist, J., Jun. 2012. The Geomechanics of $\mathrm{CO}_{2}$ Storage in Deep Sedimentary Formations. Geotechnical and Geological Engineering 30 (3), 525-551.

Rutqvist, J., Tsang, C.-F., 2002. A study of caprock hydromechanical changes associated with $\mathrm{CO}_{2}$-injection into a brine formation. Environmental Geology 42 (2-3), 296-305.

URL http://dx.doi.org/10.1007/s00254-001-0499-2

Rutqvist, J., Vasco, D. W., Myer, L., 2010. Coupled reservoir-geomechanical analysis of $\mathrm{CO}_{2}$ injection and ground deformations at In Salah, Algeria. International Journal of Greenhouse Gas Control 4 (2), 225 - 230, the Ninth International Conference on Greenhouse Gas Control Technologies. URL http://www. sciencedirect.com/science/article/pii/S1750583609001388 
1 Snir, M., Otto, S., Huss-Lederman, S., Walker, D., Dongarra, J., 1998. MPI-

2 The Complete Reference, Volume 1: The MPI Core, 2nd Edition. MIT

3 Press, Cambridge, MA, USA.

${ }_{4}$ Tsingas, C., Marhfoul, B. E., Satti, S., Dajani1, A., 2011. Diffraction imaging

$5 \quad$ as an interpretation tool. First Break 29 (29), 57-61.

6 Vasco, D. W., Ferretti, A., Novali, F., 2008. Estimating permeability from

7 quasi-static deformation: Temporal variations and arrival-time inversion.

$8 \quad$ Geophysics 73 (6), O37-O52.

9 URL http://geophysics .geoscienceworld.org/content/73/6/037. abstract

10

Vasco, D. W., Rucci, A., Ferretti, A., Novali, F., Bissell, R. C., Ringrose, P. S., Mathieson, A. S., Wright, I. W., 2010. Satellite-based measurements of surface deformation reveal fluid flow associated with the geological storage of carbon dioxide. Geophysical Research Letters 37 (3), 1-5.

URL http://dx.doi .org/10.1029/2009GL041544

Virieux, J., 1986a. P-sv wave propagation in heterogeneous media: Velocitystress finite-difference method. Geophysics 51 (4), 889-901.

URL http://library.seg.org/doi/abs/10.1190/1.1442147

Virieux, J., 1986b. P-SV wave propagation in heterogeneous media; velocity-stress finite-difference method. Geophysics 51 (4), 889-901. URL http://geophysics.geoscienceworld.org/content/51/4/889. abstract

Virieux, J., Madariaga, R., 1982. Dynamic faulting studied by a finite difference method. Bulletin of the Seismological Society of America 72 (2), 
1

345-369.

URL http://www. bssaonline.org/content/72/2/345. abstract

Zhang, R., Song, X., Fomel, S., Sen, M. K., Srinivasan, S., 2013. Timelapse seismic data registration and inversion for co2 sequestration study at cranfield. GEOPHYSICS 78 (6), B329-B338.

URL http://dx.doi.org/10.1190/geo2012-0386.1

Zhang, R., Song, X., Fomel, S., Sen, M. K., Srinivasan, S., 2014. Timelapse pre-stack seismic data registration and inversion for co2 sequestration study at cranfield. Geophysical Prospecting 62 (5), 1028-1039.

URL http://dx.doi.org/10.1111/1365-2478.12114

Zhang, R., Vasco, D., Daley, T., Harbert, W., 2015. Characterization of a fracture zone using seismic attributes at the in salah $\mathrm{CO}_{2}$ storage project. Interpretation 3 (2), A1-A14.

URL http://dx.doi.org/10.1190/INT-2014-0106.1 


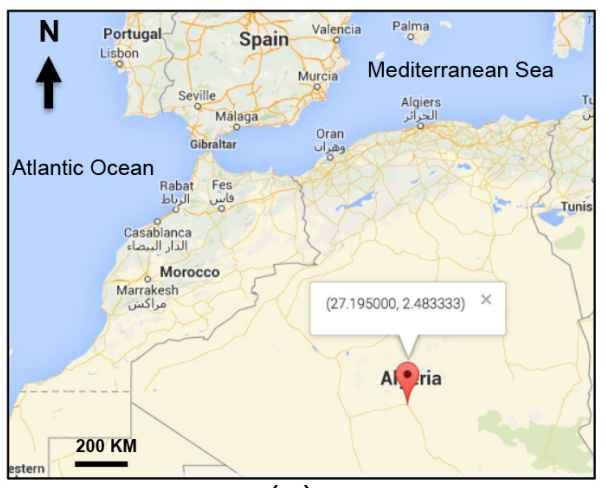

(a)

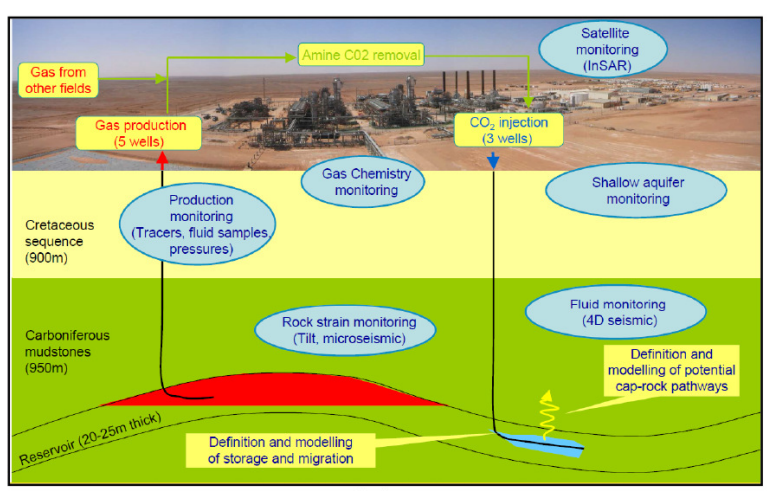

(b)

Figure 1: (a) shows the location of In Salah project with Latitude (27.195) and Longitude (2.483333) highlighted; (b) shows the schematic workflow the $\mathrm{CO}_{2}$ injection 


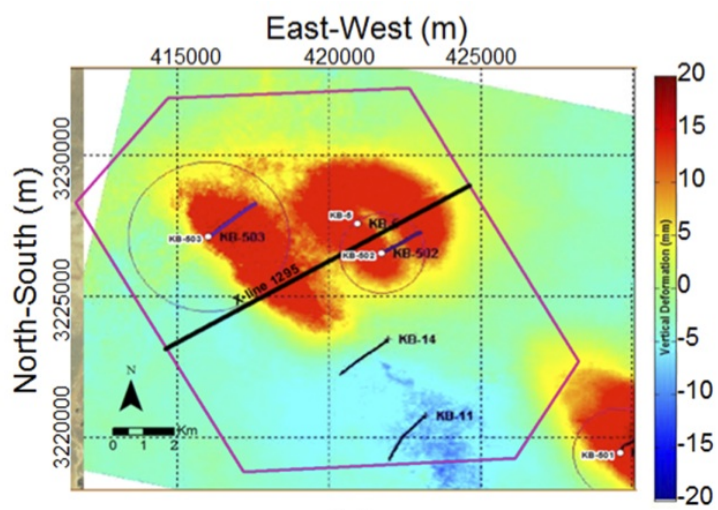

(a)

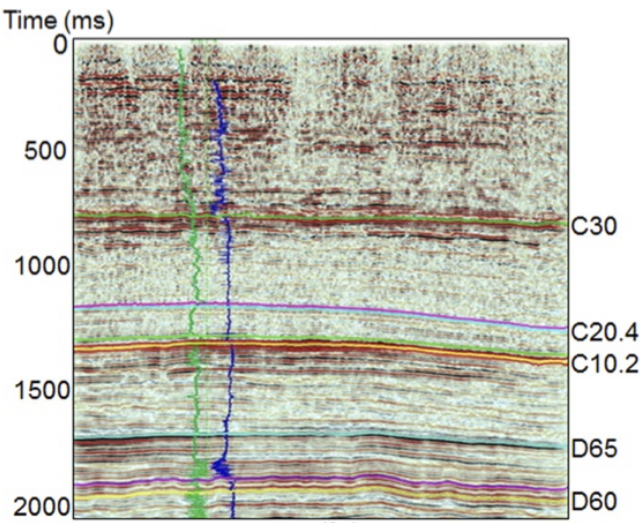

(b)

Figure 2: (a) Surface deformation after 5-year $\mathrm{CO}_{2}$ injection with seismic survey boundary polygon overlaid; (b) surface seismic image at cross-line 1295 (Gibson-Poole and Raikes, 2010). 


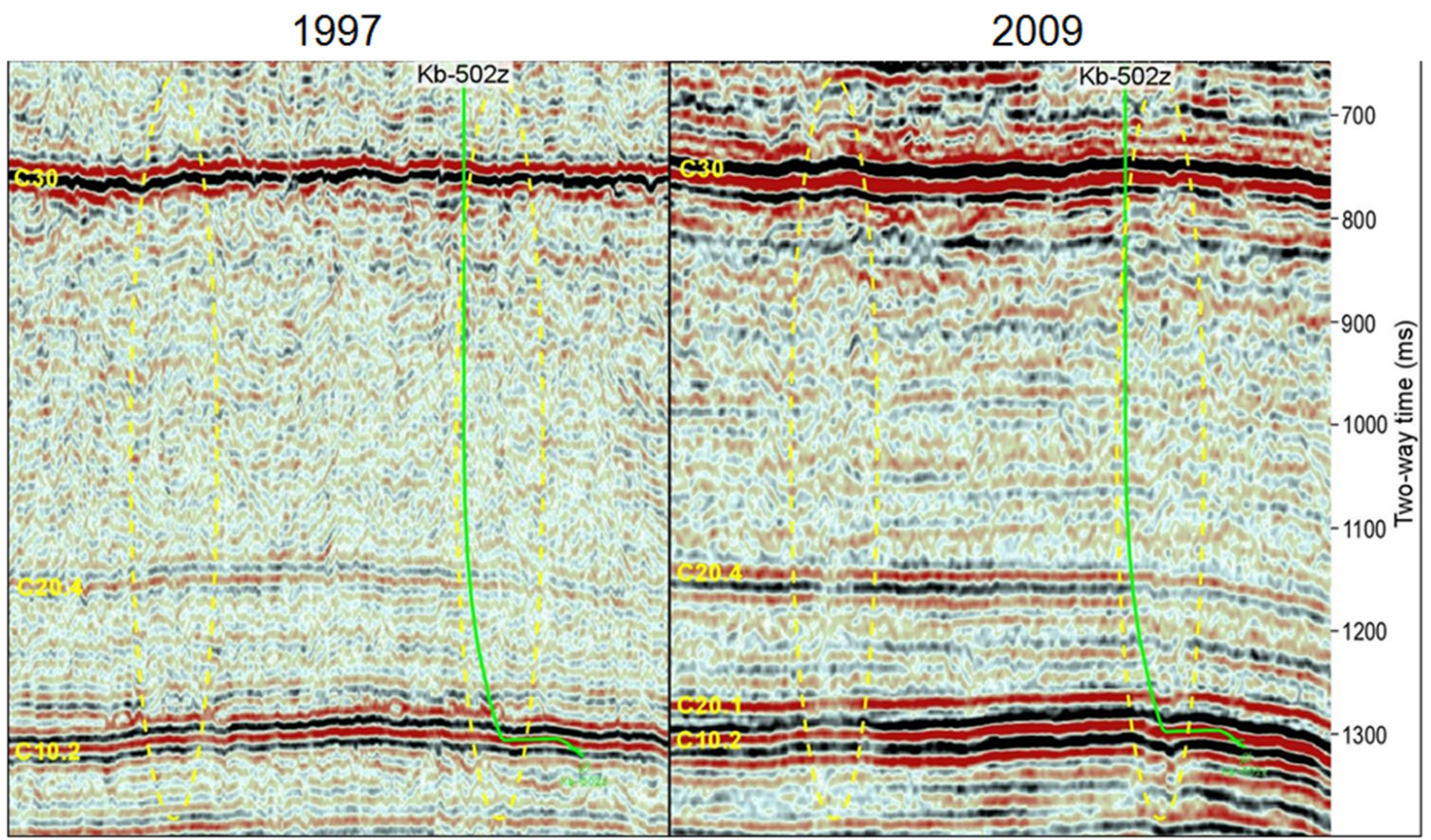

(a)

(b)

Figure 3: Cross-line 1323 with injection well 502 inserted. A possible push-down event is located at horizontal portion of the injection well KB-502 (Gibson-Poole and Raikes, 2010). 


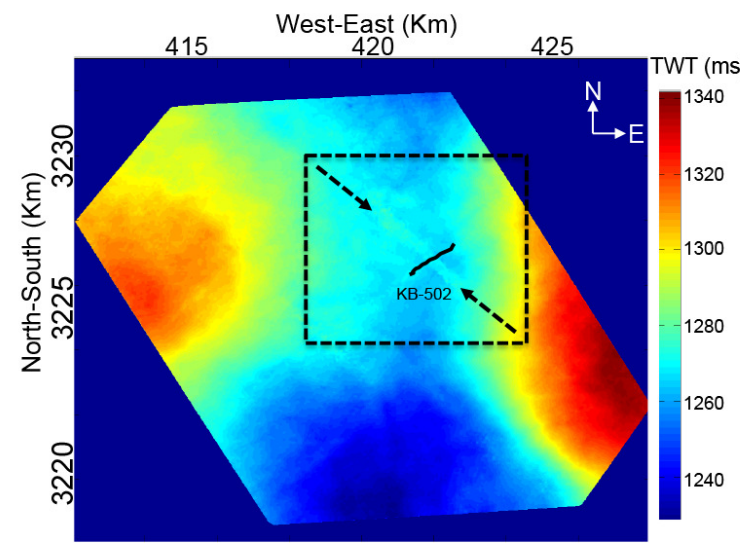

(a)

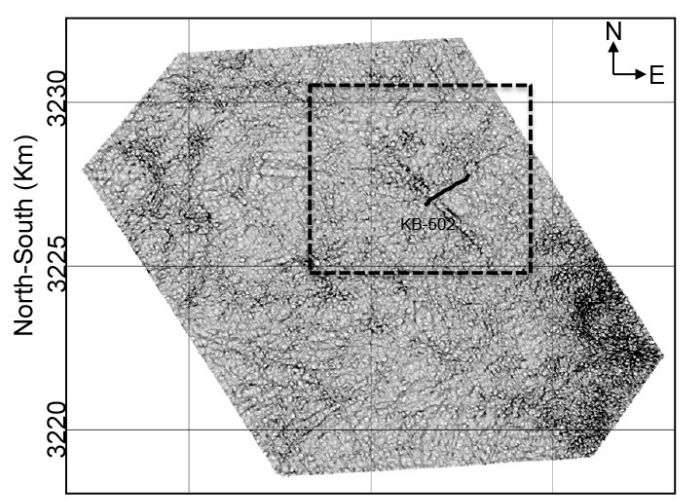

(c)

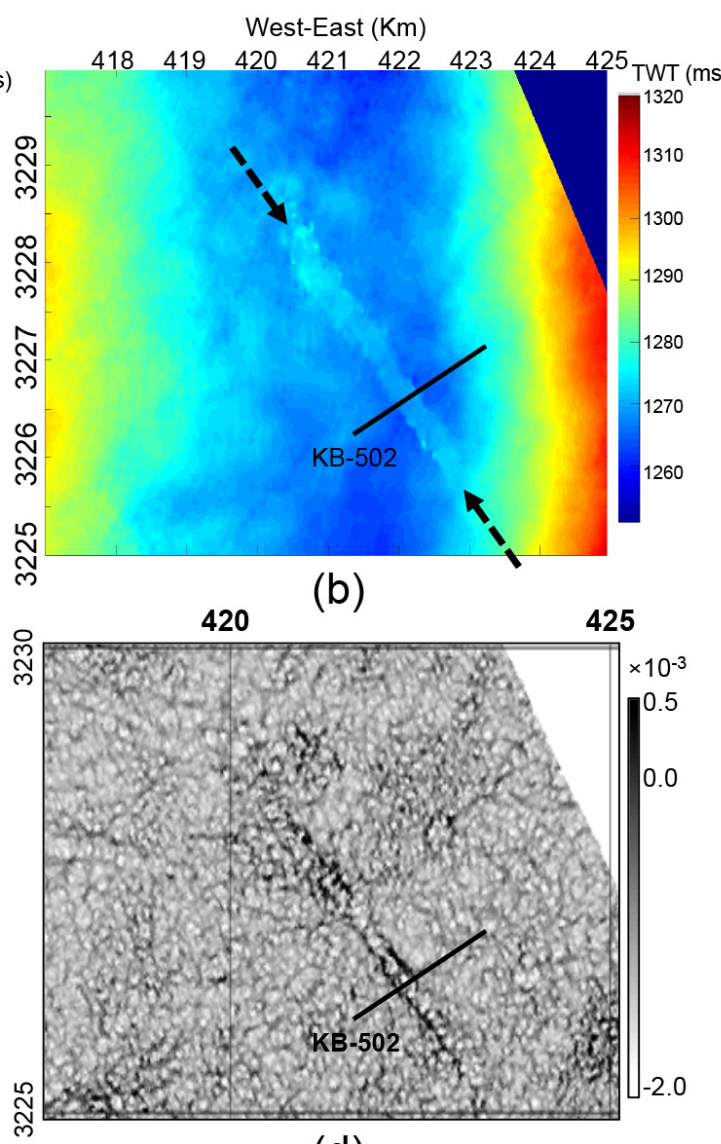

(d)

Figure 4: (a) shows mapped surface at the bottom of the overlain shale, and (b) shows the zoomed view within the black dashed rectangle of (a). (c) shows the most positive curvature along the same surface, and (d) shows the zoomed view within the black dashed rectangle in (c). 


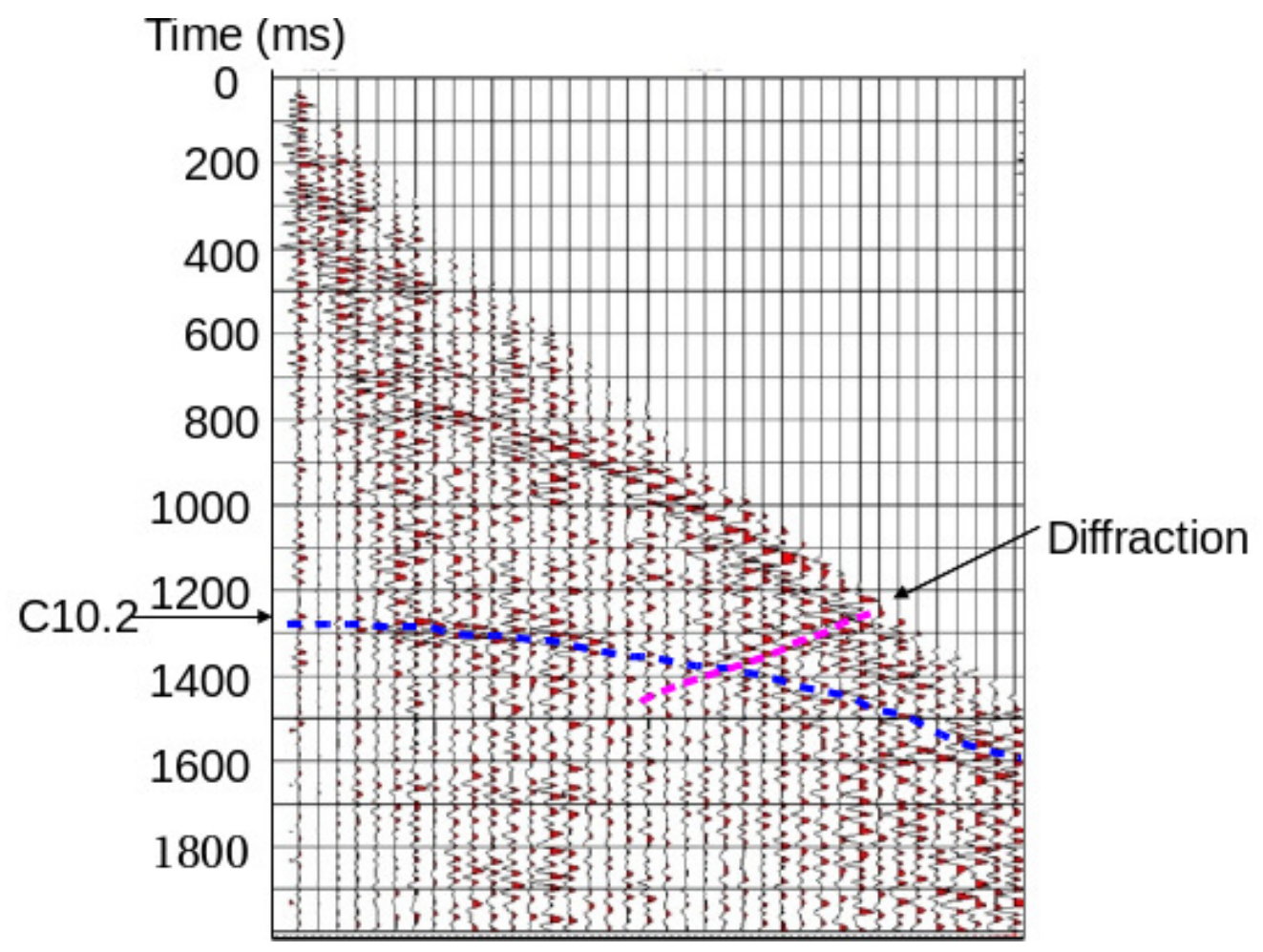

Figure 5: A common mid-point gather, with mid-point close to the fracture zone. A potential diffraction event scattered from the zone is indicated. 

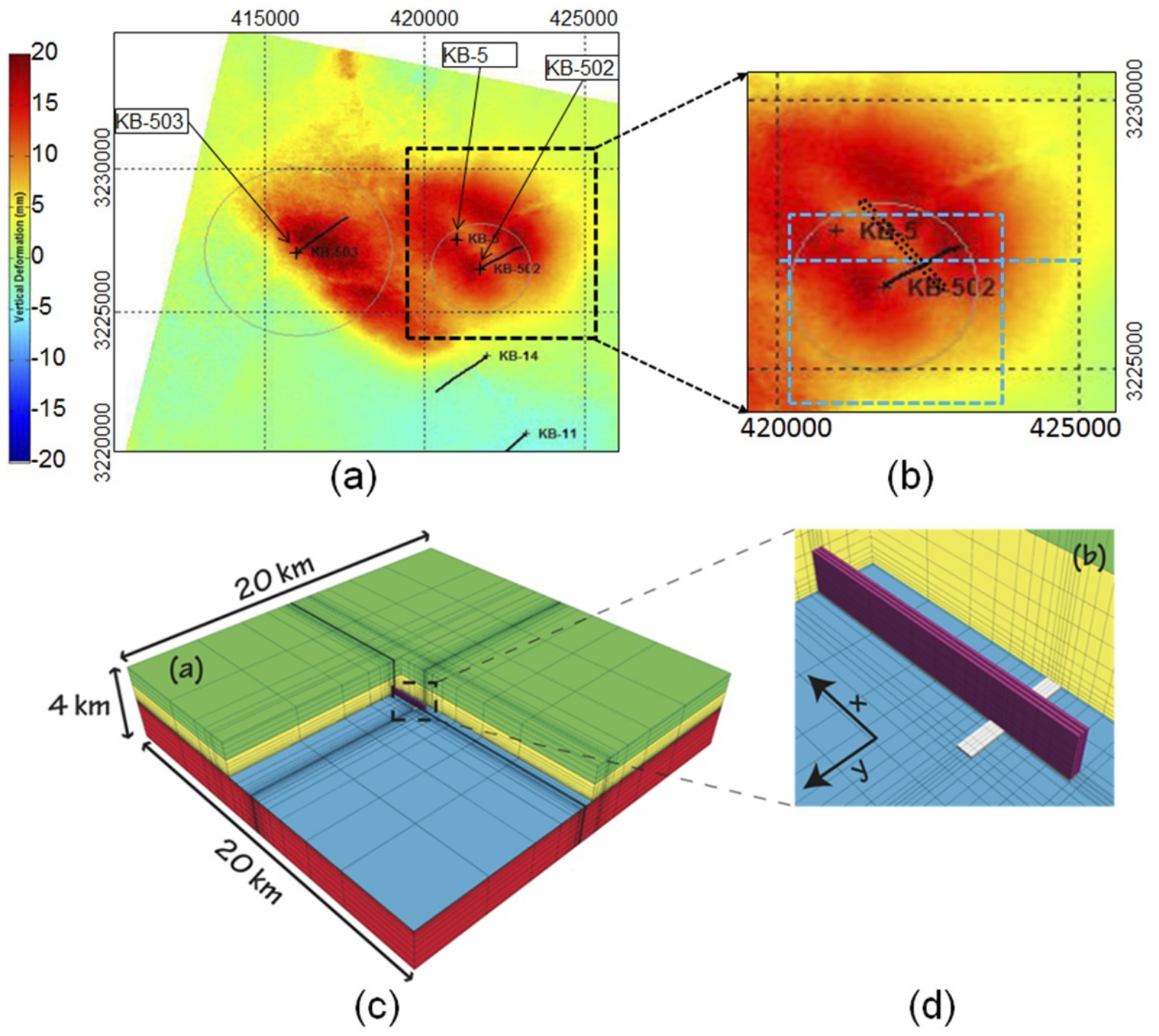

Figure 6: (a) shows complete 3D geomechnical model; and (b) shows zoomed view of the model. 


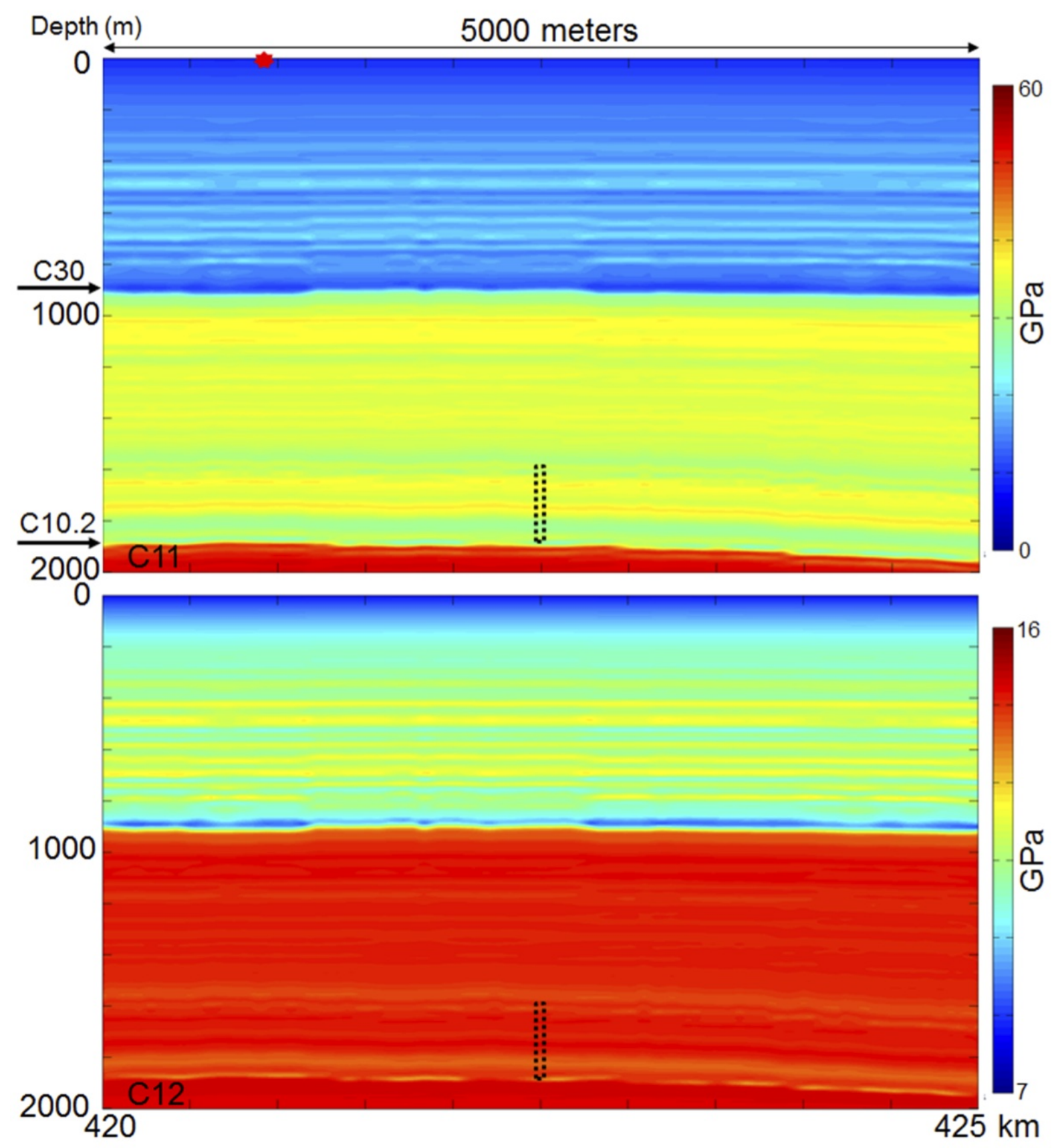

Figure 7: 2D elastic moduli model of stiffness tensors $C_{11}$ and $C_{12}$ are shown in the upper and lower figures. The black arrows on the left indicate the two major horizons of C30 and C10.2 as in Figure 2. 


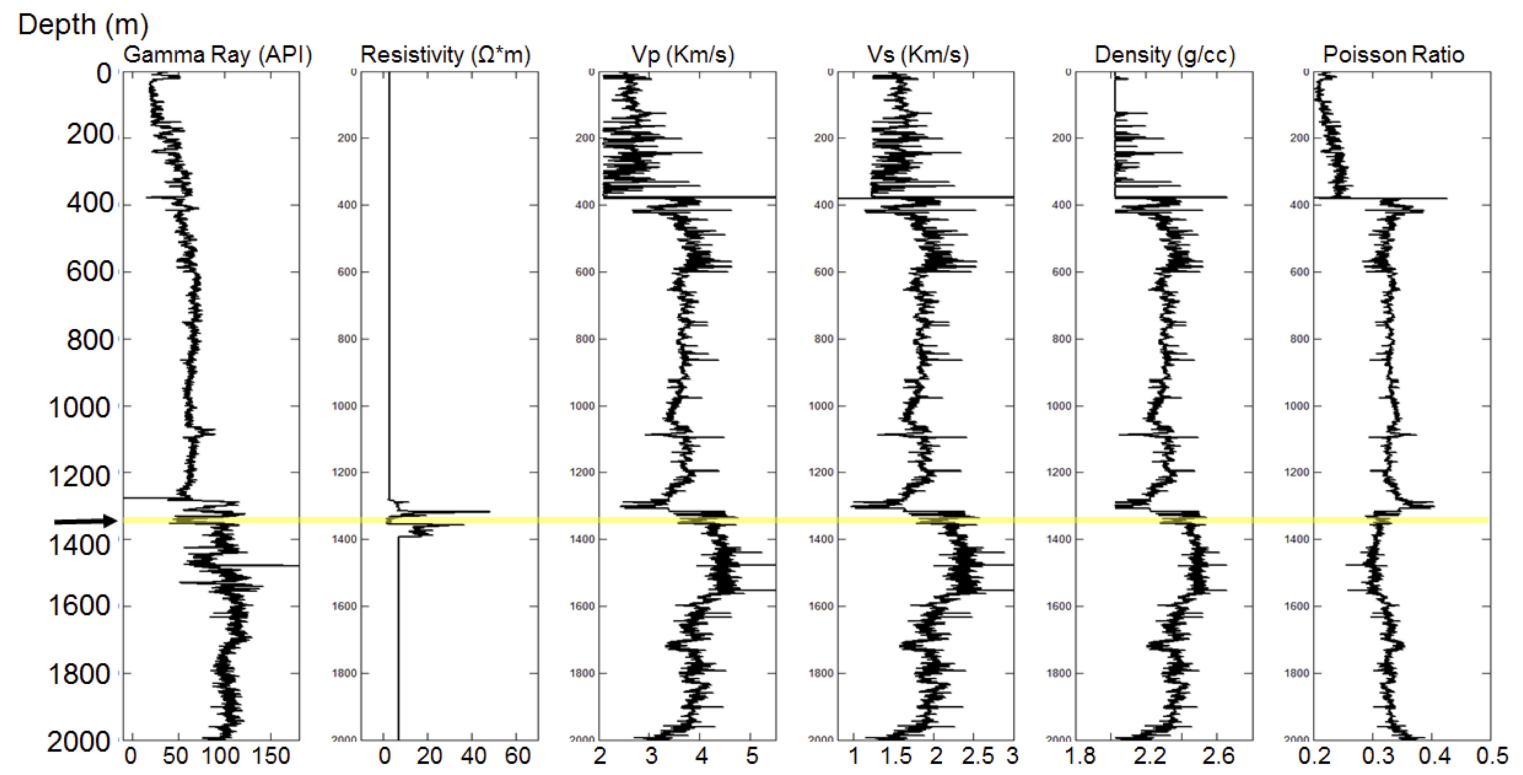

Figure 8: Well-log data at well KB-5, including Gamma ray, resistivity, $V_{p}, V_{s}$, density and poisson ratio. 


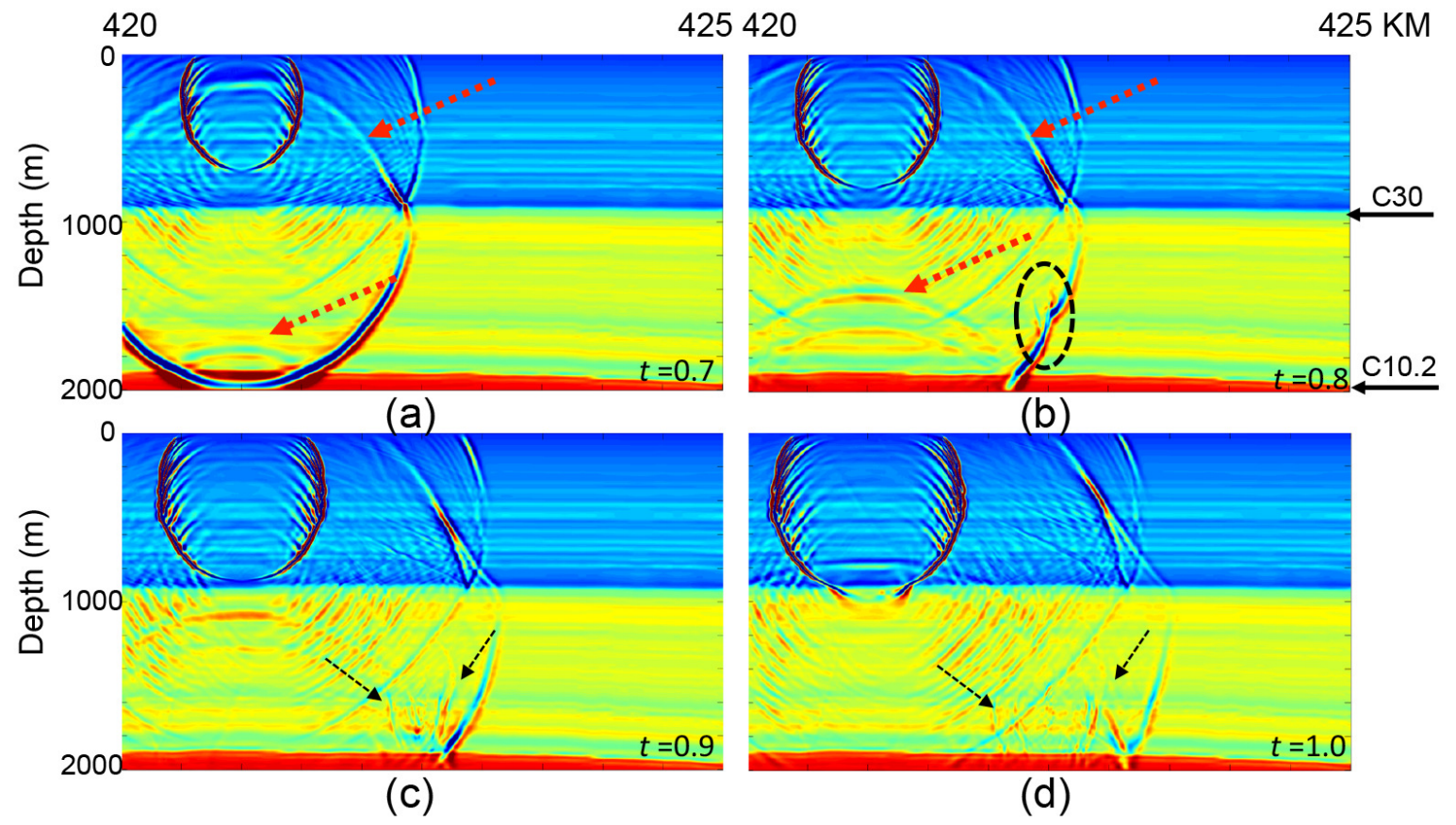

Figure 9: Snapshots of wavefields of vertical component at (a) $0.7 \mathrm{~s}$, (b) $0.8 \mathrm{~s}$, (c) $0.9 \mathrm{~s}$ and (d) $1.0 \mathrm{~s}$. 


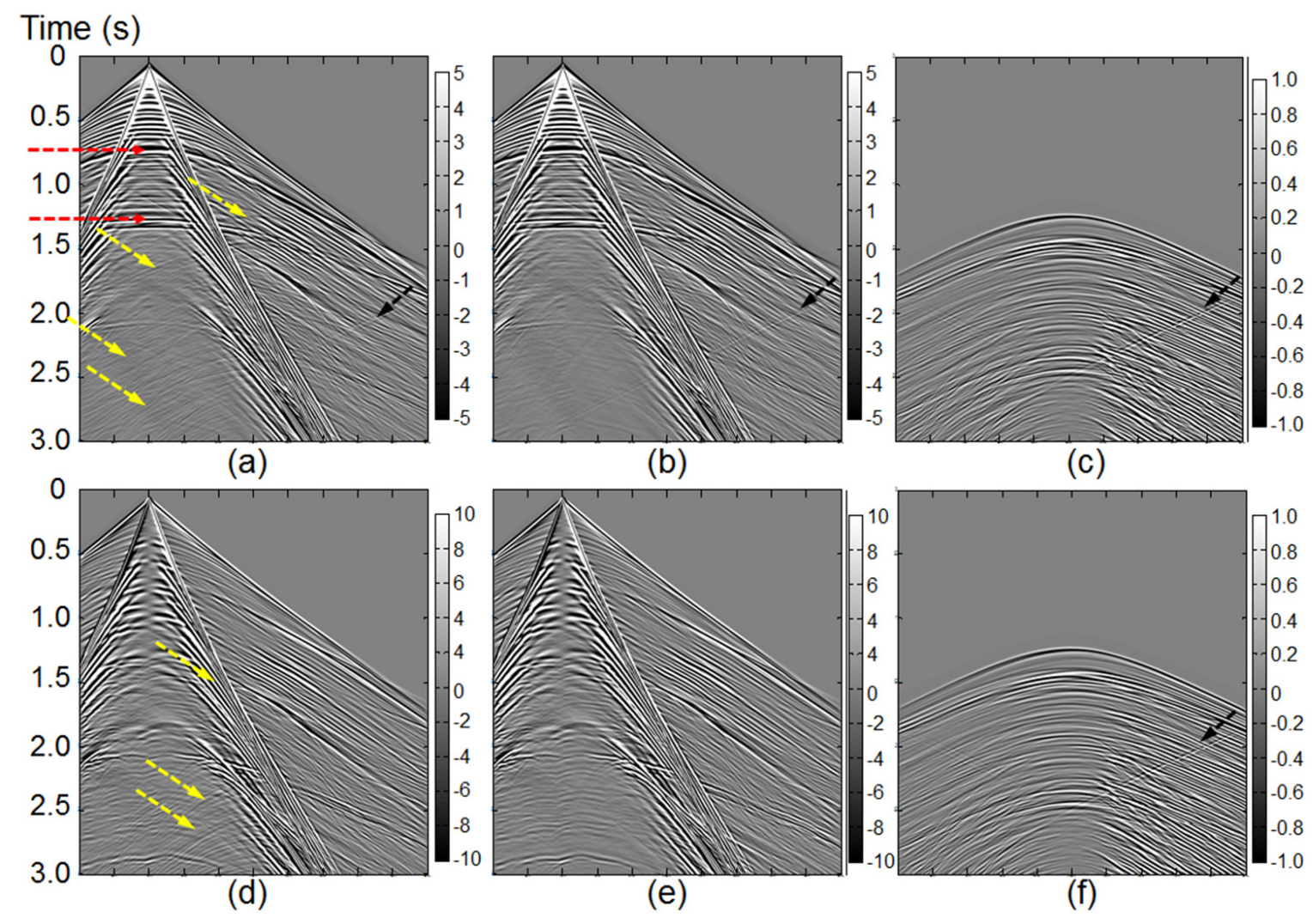

Figure 10: (a) and (d) show received vertical and horizontal seismograms with fracture embedded; (b) and (e) show vertical and horizontal seismograms without fracture zone; (c) and (f) show their differences. 

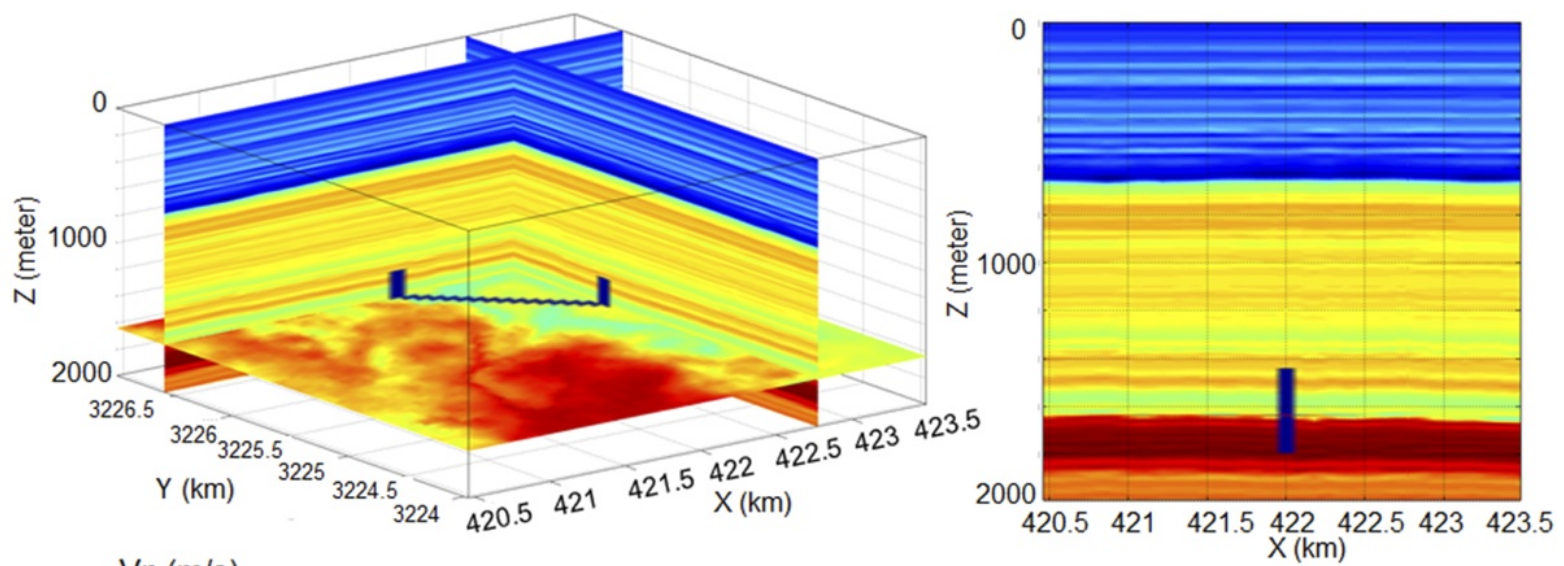

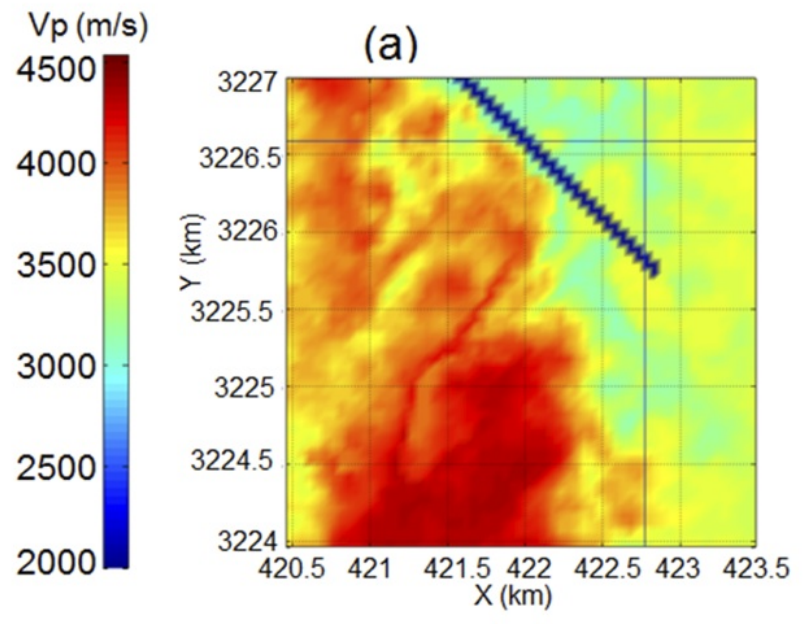

(c)

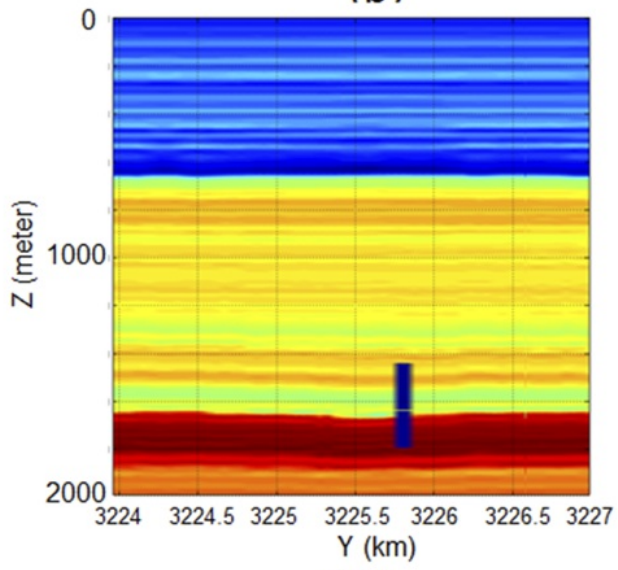

(d)

Figure 11: (a) shows 3D $V_{p}$ model with three plain view; (b) shows a slice of $V_{p}$ in X-Z plain; (c) shows a slice of $V_{p}$ in X-Y plain; (d) shows a slice of $V_{p}$ in Y-Z plain. 


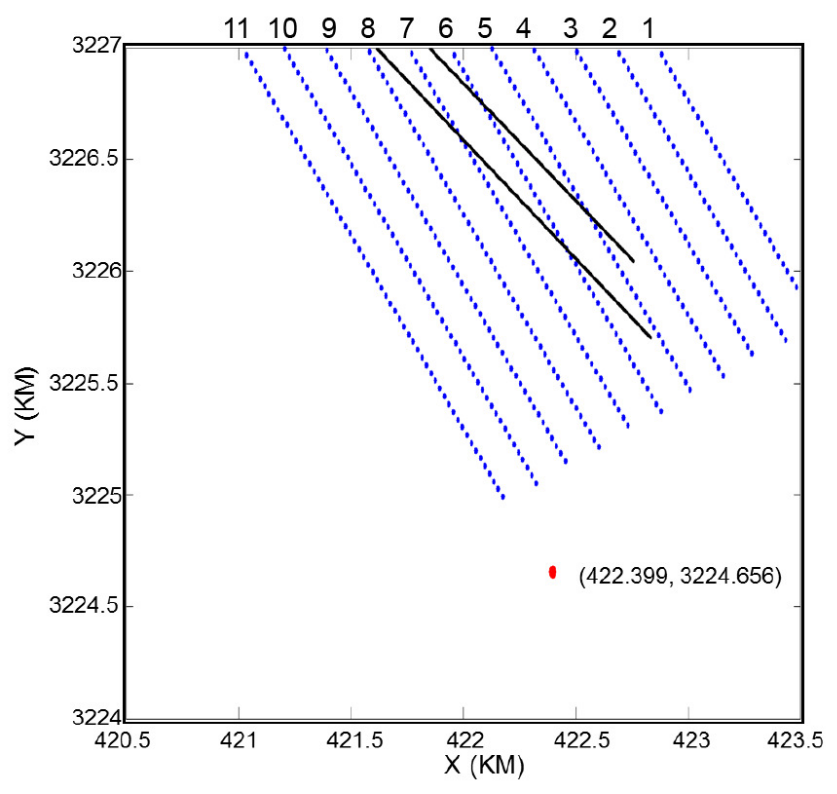

(a)

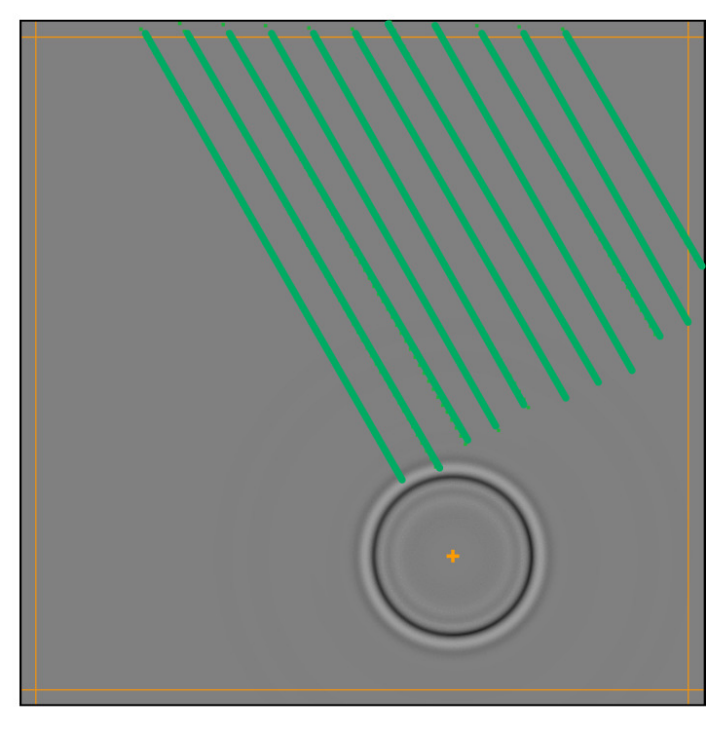

(b)

Figure 12: (a) shows acquisition geometry of a shot gather with source pointed in red and receiver locations highlighted in blue; (b) shows wavefield of vertical component at surface at $0.5 \mathrm{~s}$ with receivers highlighted in green lines. 


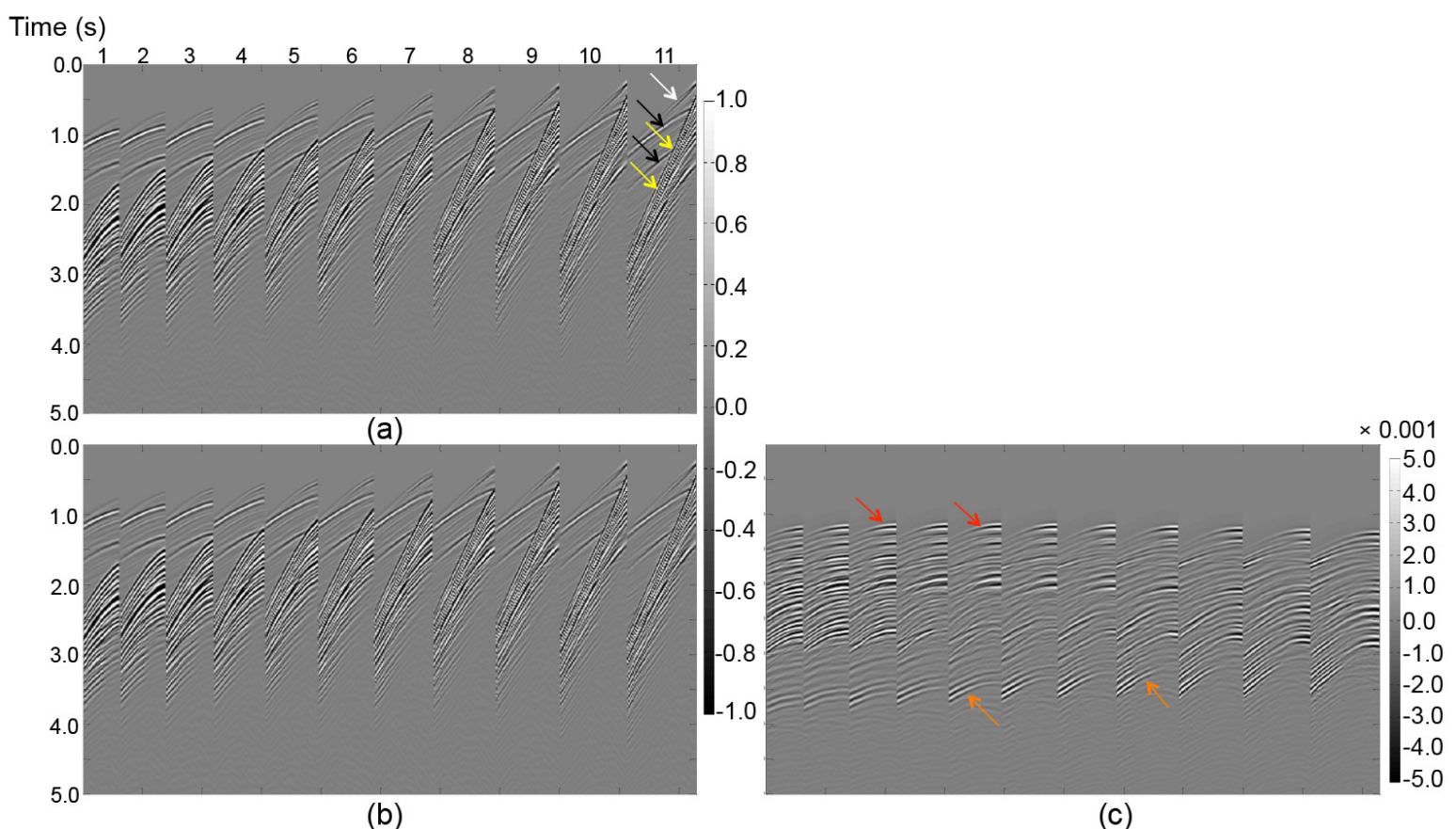

Figure 13: Received vertical component seismic data at surface: (a) with fracture embedded; (b) without fracture; (c) their difference. In the figure (a), white arrow indicates the head wave; black arrows indicate reflection events and yellow arrows indicate surface wave events. In the figure (c), red arrows indicate the first arrival of the diffraction wave and orange arrows indicate the diffraction wave from the end of the fracture zone. 


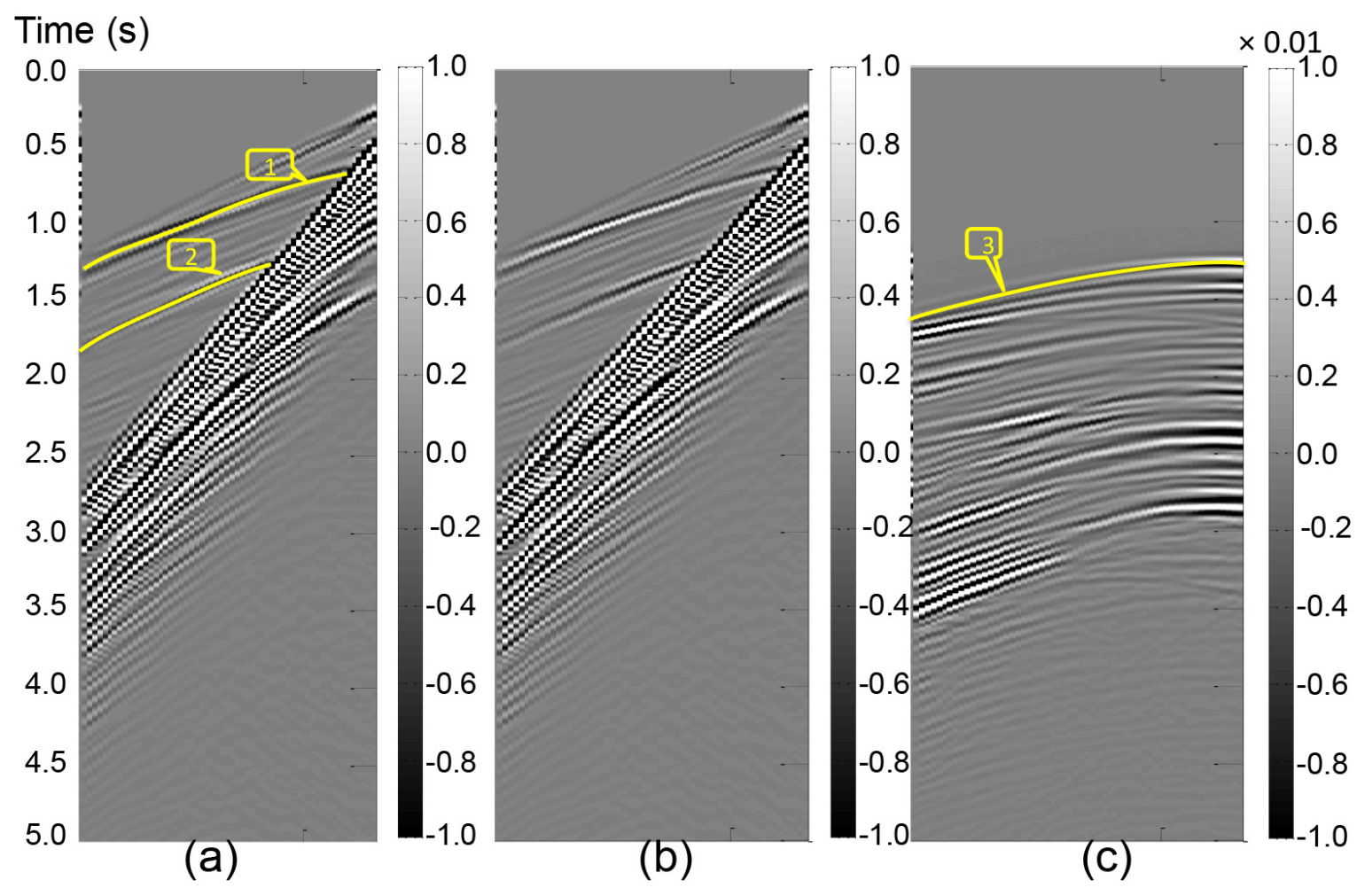

Figure 14: Shot gathers of vertical component at line 11 in Fig. 13: (a) with fracture; (b) without fracture; (c) their difference. Two reflections are highlighted as 1 and 2. First arrival of diffraction is highlighted as 3 . 


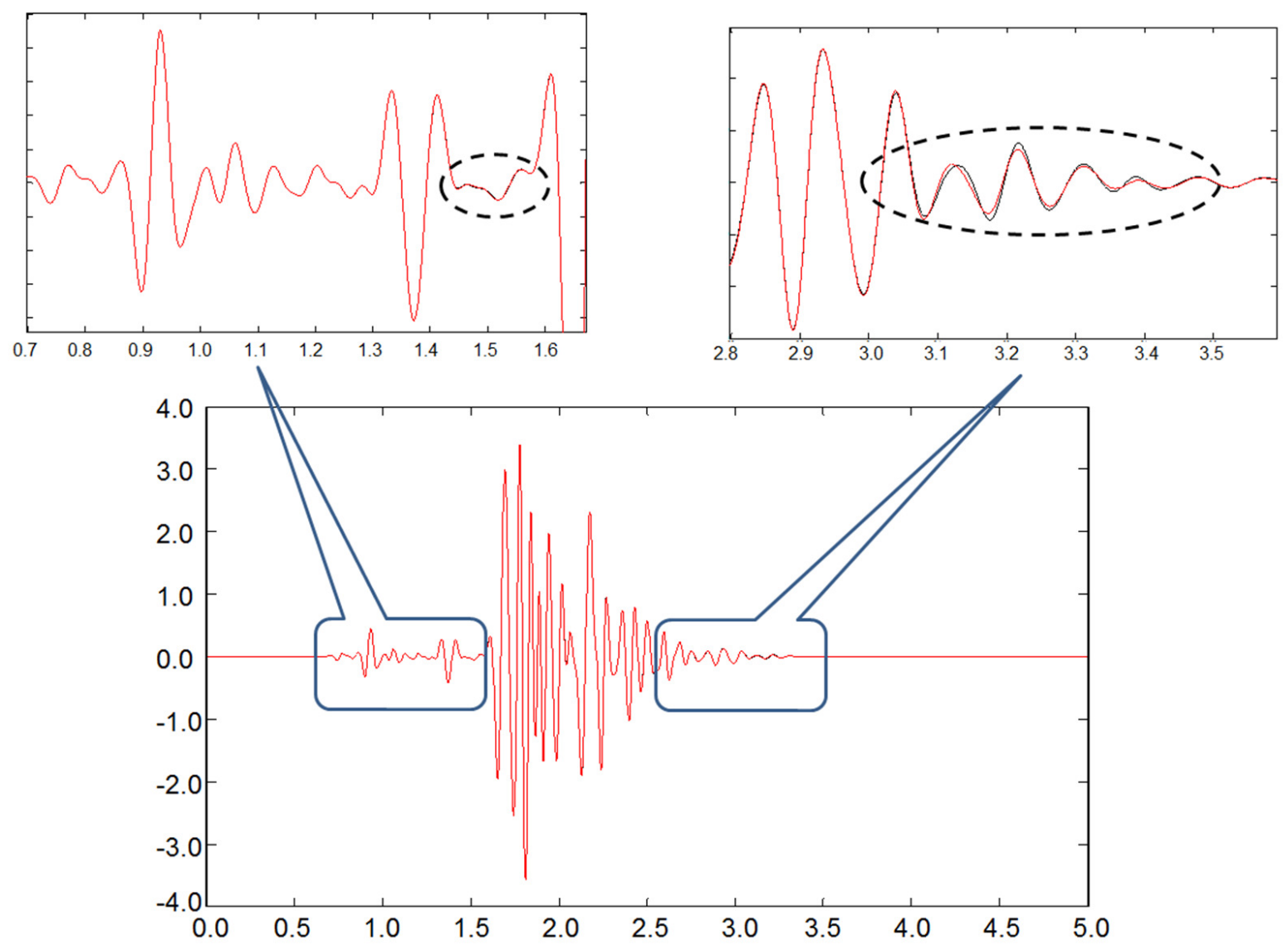

Figure 15: Overlain display of trace No. 10 in Fig. 14a and b, where red seismogram is modeled with fracture embedded and black seismogram is without fracture embedded. 

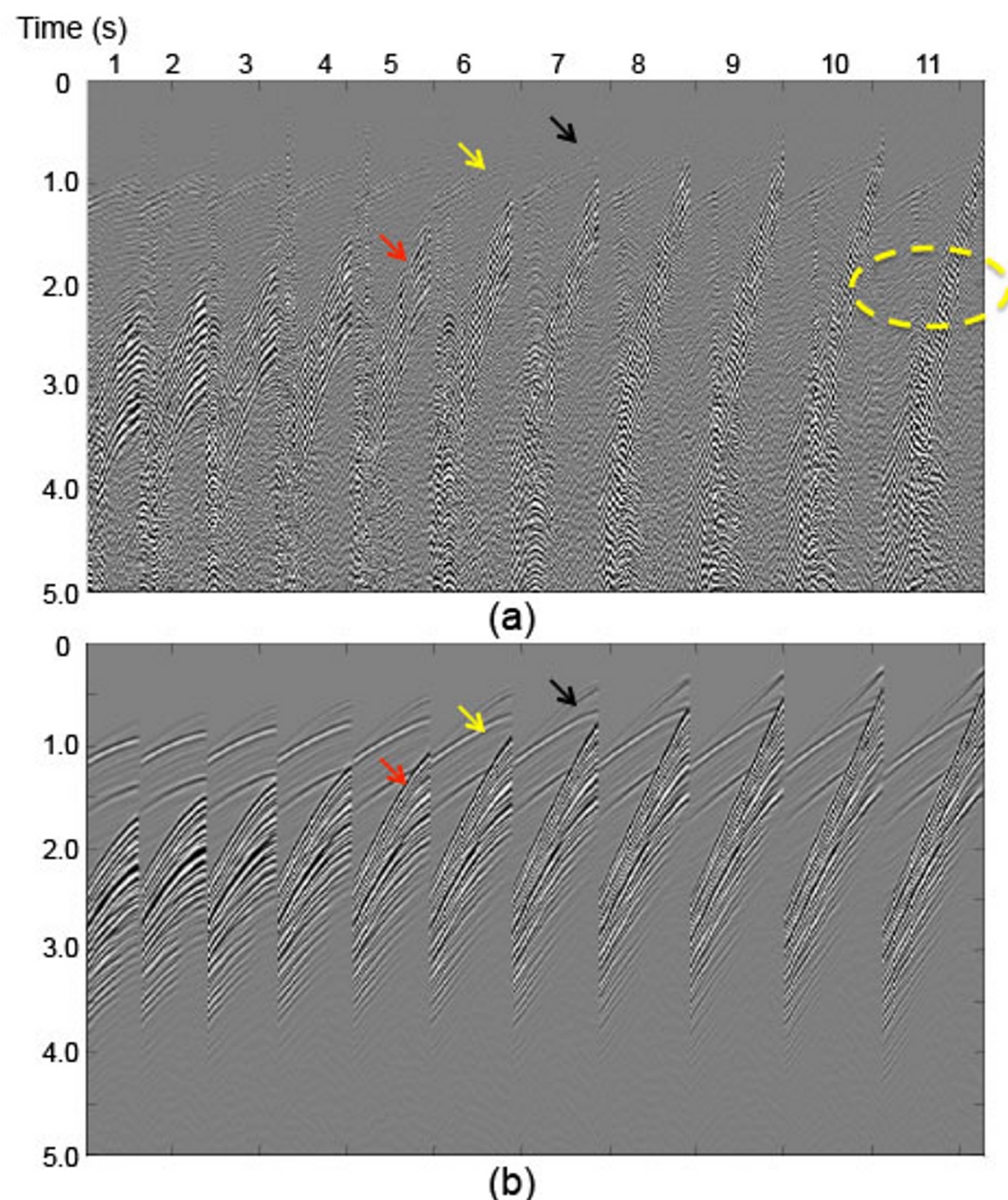

Figure 16: Comparison between real and modeled shot gathers: (a) real field raw shot gathers, and (b) modeled shot gathers from Fig. 13. Indicated on the figures are head waves (black arrows), first reflection waves (yellow arrows) and surface waves (red arrows). 